\title{
Investigating the Intrinsic Motivation and Native Language Effect in Second Language Learning
}

\author{
LIU Fulan, CHEN Yu \\ Jiangxi Normal University, Jiangxi, China
}

\begin{abstract}
In Brown's Principle of Language Learning and Teaching, we can learn a great deal about language acquisition principles. He put forward the most influenced 12 principles to refresh our teaching cognition. The authors chose two principles to further discuss and would give some pedagogical suggestions. Intrinsic motivation refers to behavior that is driven by internal rewards. In other words, the most powerful rewards are those that are intrinsically motivated within the learners. Because the behavior stems from needs, wants, or desires within oneself, the behavior itself is self-rewarding; therefore, no externally administered reward is necessary at all. Nowadays, the intrinsic motivation plays an irreplaceable role in students' learning, and it can promote students' learning ability. Another principle is the native language effect. When learning a foreign language, the native language always plays a role in it. Here, there are two aspects: positive and negative transfer. How to turn the students' negative transfer into positive transfer and encourage students to continue keeping positive transfer will be an important task that teachers may meet in the classroom. This paper mainly discusses the functions of the intrinsic motivation and the native language effect principles in students' learning and English teaching in second language. This study aims to encourage English teachers to adopt the two principles during teaching process and enable students to enjoy the process of learning English. In the end, the authors also give some pedagogical implications to second language teaching and expect to improve students’ confidence in second language learning.
\end{abstract}

Keywords: intrinsic motivation, native language effect, English teaching

\section{Introduction}

The great importance of second language learning has attracted the attention of many language teachers and researchers, especially studying theories. There are still some problems unsolved in the course of English teaching, such as the poor performance and the low confidence of students. The reason why the students cannot make satisfactory progress in English learning is that there is a lack of theoretical guidance for improving students' English learning. The situation surely required teachers to find out the influence factors and connect them with practice in order to better implement teaching methods. It is the teacher's responsibility to stimulate the students' English learning motivation and help them overcome language obstacles. English teachers would give proper comments on students' performance for the sake of making English learning more effective. Hence, the intrinsic motivation and the native language effect should be highlighted in English classroom. As a teacher, he/she should make full use of the sufficient time to provide a more convincible evidence for the long-time 
effectiveness of the two principles. Based on the theories, teachers can make a summary and apply them to the teaching practice.

\section{A Discussion of Intrinsic Motivation}

Krashen (1982) claimed that learners with high motivation, self-confidence, a good self-image, and a low level of anxiety are better equipped for success in second language acquisition. Low motivation, low self-confidence, and debilitating anxiety can raise the affective filter and form a "mental block" that prevents comprehensible input from being used for acquisition. From this, we can know that low motivation is one of factors that prevent language learning. Intrinsic motivation has been studied since the early 1970s. The phenomenon of intrinsic motivation was first acknowledged in experimental studies of animal behavior. In these studies, it was evident that the organisms would engage in playful and curiosity-driven behaviors in the absence of reward. Motivation, defined as the impetus to create and sustain intention and goal-seeking acts (Ames, 1992), is important because it determines the extent of the learner's active involvement and attitude toward English learning. Similarly, some researchers in China have found that individuals with stronger motivation is relatively persistent in study compared with those with weaker motivation, thus tend to achieve greater progress (Shao, 1999).

As far as the source of motivations is concerned, they are intrinsic motivation and internal motivation. Intrinsic motivation is related to the internal factor of foreign language learners, which comes from personal interests. It also occurs when people are internally motivated to do something because it either brings them pleasure, they think it is important, or they feel that what they are learning is significant. Extrinsic motivation refers to foreign language learners who are stimulated by external forces to learn English. For instance, they may receive rewards (like money or good grades).

Maslow (1970) claimed that intrinsic motivation is clearly superior to extrinsic. According to his hierarchy of needs discussed above, we are ultimately motivated to achieve "self-actualization" once the basic physical, safety, and community needs are met. No matter what extrinsic rewards are present or absent, we will strive for self-esteem and fulfillment. So, teachers need to prepare their students for the adult world, where concrete rewards are few. We want students to be excited about coming to school, interested in acquiring new skills and eager to explore new fields. We want them to feel good about themselves when they succeed because it gives them a sense of accomplishment. In short, we need to deeply understand the intrinsic motivation of students by learning the theory or observing. Compared with language competence, motivation plays a great role during the process of foreign language acquisition (Gardner \& Lambert, 1972). If teachers cannot stimulate a motivation of students, they cannot lead to a higher production.

\section{A Discussion of the Native Language Effect}

Today, linguists are paying more and more attention to native language transfer. One theory is universal grammar raised by Chomsky. Another one is linguistic universals raised by Greenberg. L1 and L2 share much in common. There are two aspects: positive transfer and negative transfer.

The students who come into contact with a foreign language will find some features of it quite easy and others extremely difficult. Those elements that are similar to his native language will be simple for him, and those elements that are different will be difficult. (Xu \& Ding, 2010) 
The majority of a learner's errors in producing the second language, especially in the beginning levels, stem from the learner's assumption that the target language operates like the native language.

The positive transfer of the native language effect often be ignored; there are many similarities between the two language. If you are able to fluently or quickly read Chinese books, you can be easier read English articles. Chomsky (1957) pointed out five basic syntaxes, which are the base of all complicated sentences, are the same in two languages.

(1) $\mathrm{S}+\mathrm{V} 1+$ predicate $\quad$ e.g., I am a teacher. (Wo shi yi wei lao shi.)

(2) $\mathrm{S}+\mathrm{V} 1$ (+ adverbial) e.g., We work hard. (Wo men gong zuo nu li.)

(3) $\mathrm{S}+\mathrm{Vt}+\mathrm{O} \quad$ e.g., He studies English. (Ta xue xi ying yu.)

(4) $\mathrm{S}+\mathrm{Vt}+$ indirect $\mathrm{O}+$ direct $\mathrm{O} \quad$ e.g., I sent him a letter. (Wo ji gei ta yi feng xin.)

(5) $\mathrm{S}+\mathrm{Vt}+\mathrm{O}+\mathrm{C} \quad$ e.g., He teaches us to study English. (Ta jiao wo men ying yu.)

Above all, the positive transfer presents the common feature between the L1 and L2; non-native students can have a better understand to acquire a foreign language.

In terms of our learning and teaching experience, we can find that the writing proficiency of the majority of Chinese students is lower than reading proficiency. The native language effect on writing is the most obvious. When writing English essays, they cannot express their ideas as freely as in Chinese. We can also observe students often put Chinese thinking in English writing. The negative transfer of the native language effect often becomes our concerns when non-native students learn foreign language. We often observe the Chinese pronunciation habits are different from English pronunciation. For one thing, psychologists and linguists show that the best age for a person to learn a foreign language is between 6 and 13 years old. And most of our students learn English beyond the best age of learning a foreign language. Students are more affected by their fixed mother tongue, which profoundly influence language thinking, language expression, and language culture. It is an important subject in English teaching to apply the mother tongue effect of Chinese to English teaching. For another, when we learn vocabulary in primary school, at first we cannot spell the words, so we were used to making a familiar pronunciation in Chinese. In this way, the development of students' English pronunciation will be easily misguide, which can be a negative transfer.

\section{Pedagogical Implications for Second Language Learning}

There is so much information the author had involved about the two principles; the analysis of the two principles both were concrete presented. We can clearly know the statement and functions of them. Therefore, it is time for us should give emphasis on the second language teaching with the two principles respectively. For different theoretical guidance, teachers can obtain various suggestions to apply it to classroom practice. English teaching is a complex and repetitive cognitive process, the paper stressed that teachers give instructions and feedback in the process of students learning with the two principles. The intrinsic motivation and the native language effect will be further connected with the real classroom teaching. The discussion of this study provides the following pedagogical implications for the teaching of second language.

\section{The Describe of the Intrinsic Motivation in Students}

In some communities in the Americas, motivation is a driving force for learning. Children are incorporated and welcomed to participate in daily activities and feel motivated to do due to a sense of belonging in their families and communities. Children's participation is encouraged and learning behavior is supported by their 
community and family. Their active participation allows them to learn and gain skills that are valuable and useful in their future. However, there are many children lack of the above awareness in China. That is say, especially for lower children, they tend to rely on their parents or friends. The intrinsic motivation is not obvious in their learning and life in young age.

As children transition from early childhood to middle childhood, their motivation will change followed by their age. This transition between childhood and adolescence increases motivations because children gain social responsibility and want to establish their social statue in the society. The only thing students can currently do is establishing the intrinsic motivation in their English learning. As a teacher, we have to learn the different responses of students in advance. So, there is a great urgency for teachers to establish intrinsic motivation in teaching process. It not only provides students with a unique opportunity to deepen them knowledge of their subjects, but also enables them to enhance their personal characters, which will greatly benefit their career in the long term. Certainly, tests and exams can incorporate some student consultation and peer evaluation. Teachers can help students to view tests as feedback instruments for self-diagnosis ad not simply for comparing one's performance against a norm. Students thus become motivated by the experience and by achieving self-knowledge.

\section{Pedagogical Implications of the Intrinsic Motivation}

In classroom, you can perform a great service to learners and to the overall process by first considering carefully what the intrinsic motives of your students are and then by designing classroom tasks that feed into those intrinsic derives. The learners perform the task because it is fun, interesting, useful, or challenging, and not because they anticipate some cognitive or affective rewards from the teacher. In classroom, finding someone intrinsically motivated at learning and someone who is truly productive. It is an important task for teachers. For example, generally, there are two students; one can learn by themselves and no rewards, and the other may learn knowledge to get rewards. However, the former will learn better in a long term and enjoy the learning process. The latter maybe gradually desire more rewards when they grow, so they will lose interests in studying, because they do not care these rewards. So, we should cultivate students a sense of independent learning, they really love studying rather than compelling to learn. It may appear that the reason some students with intrinsic motivation are more engaged and perform better in class activities. Next, teachers are enablers, not rewarders. Therefore, when you teach, you focus less on how to administer immediate or tangible rewards and more on how to get students to tune in to their potential and to be challenged by self-determined goals. Finally, you help learners to take charge of their own learning through setting some personal goals and utilize learning strategies.

As a teacher, when we perceive the progress of students' grades, the first thing we should do is acknowledging their progress and encouraging them to make a better achievement. The role of the teacher is an organizer or a guider rather than authority. The teacher is really involved in the teaching process by giving the students instructions to necessary help them finish their assignments. When we face the errors of students, it is best to guide them correct errors and tell students that you always believe them and hope them make a great progress. Most importantly, the teaching of English is student-center. In the teaching process, teachers are critical to give students the help of two aspects: the time to expand and organize ideas on English learning. So, teachers will find the process of teaching enables students to discover new perspectives and new language forms to express their views. Only in this way, students intrinsic motivation can be stimulated by us and remain it forever. 


\section{Pedagogical Implications of the Native Language Effect}

The native language effect is not a single activity in the teaching process of English, so the teacher should encourage the students to read widely in order to enlarge the vocabulary, broaden their horizon, and improve their ability of using the second language. Teachers must realize that learners' errors stand out like the tips of icebergs giving us salient signals of an underlying system at work. Errors are, in fact, window to a learner's internalized understanding of the second language.

Proficiency in second language may show you have a powerful learning ability, which you enable to avoid the negative transfer in your native language and make full use of its advantages. The difficulties in perceiving target language speech sounds depend upon the relations between the native and foreign language. Foreign speech sounds which acoustically resemble the native sounds, but are phonologically distinct, cause serious problems. Since these sounds are perceived in accordance with the native system. It also may cause potential failures in second language learning. When we notice the native language effect to the classroom, interference will most often be the focus of teachers' feedback in the classroom. With frequently making mistakes in second language, it is possible that students are confused and cannot distinguish them from their native language. At this time, you must deeply understand their mother tongue acquisition and guide them to learn the second language in this way. We believe it perhaps need lots of time but will be successful in the end.

In the classroom, students maybe cannot understand what teachers say in target language, because non-native students are more likely to accustom to their native language. The second language use in their classroom is difficult to them at first time. Ideally, every successful learner will hold on to the positive transfer of the native language and discard the negative transfer. In addition, it may be that the learning process may affect the native language. The learning environment is essential for non-native students. The frequently use the native language may also hinder the development of the second language learning.

\section{Conclusion}

For the intrinsic motivation, the authors found the establishment of intrinsic motivation is not easy for students or teachers. Teachers should try their best to guide students gradually to form intrinsic motivation. Teachers can use different methods to achieve this goal that state above. We can see that the intrinsic motivation can keep things always run and improve their spirits. Teachers who connect with students and give them lots of opportunities to participate in their own learning are generally successful at encouraging intrinsic motivation. When students know that their teachers really want to hear their ideas and opinions about what they are studying, they feel like they are part of the learning process.

For the native language effect, there are two effects: positive and negative transfer. When it comes to the negative transfer, teachers are required to guide students gradually change and build an academic atmosphere of the second language. And then students can unconsciously communicate with others in this language. As for positive transfer, we should encourage students to continue and form a critical thinking. In our country, most people choose English as the second language. Many studies show that English learners rely on their mother tongue in most time, especially in writing and reading. English and Chinese are similar in grammatical structure, such as sentence composition and its structure. Both Chinese and English share some common in subject, predicate, object, attribute, and adverbial. If we can understand or mastery our native language before learning the second language, it will lay a good foundation for English. 
Based on the analysis above, teachers should guide students to know about the essence of negative language transfer and overcome rather than avoid using or knowing the language differences. At the same time, the intrinsic motivation is the treasure for second language learning. Teachers are obliged to stimulate students' motivation and take a positive attitude toward them. By perceiving and internalizing connections between practice and theory (principles derived from research), your teaching is likely to be "enlightened".

\section{References}

Ames, C. (1992). Classroom, goals, structures and student motivation [J]. Journal of Educational Psychology, (73), 411-418.

Diaojitian. (2001). A brief analysis of the positive and negative effects of the native language transfer. English Study, 24(1).

Dornyei, Z. (1998). Motivation in second and foreign language learning. Language Teaching, 31(3), 117-135.

Douglas Brown, H. (2001). Teaching by principles: An interactive approach to language pedagogy. Beijing: Foreign Language Teaching and Research Press.

Gardner, R C. (2007). Integrative motivation and second language acquisition. In Z. Dornyei and R. Schmidt (Eds.), Motivation and second language acquisition. Honolulu, HI: University of Hawaii at Manoa.

Gardner, R. C. \& Lambert, W. E. (1959). Motivation variable in Second Language Acquisition [J]. Canadian Journal of Psychology, (13), 266-272.

Gardner, R. (1985). Social psychology and second language learning: The role attitudes and motivation. London: Edward Arnold.

Huang, Z. L. (2011). Linguistics A course book. Beijing: Peking University Press.

Krashen, S. (1982). Principles and practice in second language acquisition. Oxford: Pergamon.

Maslow, A. H. (1970). Motivation and Performance. New York: John Wiley and Sons.

Peltola, M. S. (2007). The effect of language immersion education on the preattentive perception of native and non-native vowel contrasts. Journal of Psycholinguistic Research, 36(1), 15-23.

Resis, S. (2012). Intrinsic and extrinsic motivation. Teaching of Psychology, 39(2), 152-156.

Shao, R. Z. (1999). Educational Psychology [M]. Shanghai: Shanghai Educational Publishing House.

$\mathrm{Xu}, \mathrm{L}$. \& Ding, L. (2010). A brief analysis of the positive and negative effects of the Native Language Transfer in English Study [J]. Science \& Technology In Formation. 